\title{
LA INVASIÓN NOTARIAL Y SU JUSTIFICACIÓN PENAL COMO MECANISMO DE PROTECCIÓN NOTARIAL: ESTUDIO DE LA LEGISLACIÓN LOCAL DE JALISCO, MÉXICO*
}

\author{
Rogelio Barba Álvarez**
}

Fecha de recibido: 16 de febrero de 2014.

Fecha de aprobado: 17 de junio de 2014.

Artículo de reflexión

Forma de citación: Barba, R. (2014). La invasión notarial y su justificación penal como mecanismo de protección notarial: estudio de la legislación local de Jalisco, México. Revista Prolegómenos. Derechos y Valores, 17, 34, 42-52.

\section{Resumen}

La fe pública en México está depositada en la función del notario, Jalisco como los demás estados del país, cuenta con una legislación local para regular la actividad del notariado, es decir, existen 32 leyes. La cuestión es que como reglamentación especial, ninguna contempla una solución a la invasión notarial de un estado a otro. Quizá resolver el problema con la amenaza penal sea un exceso, sin embargo, en este estudio el objetivo es demostrar su viabilidad. Se propone diseñar un tipo penal autónomo, que detenga la invasión notarial, toda vez que ocasiona, como delito pluriofensivo, distintas afectaciones a bienes jurídicos, el primero de ellos la credibilidad de la fe pública. La creación del tipo penal invasión notarial se sustenta en la teoría del principio personalístico, para fundar un delito que es necesario en una sociedad en evolución respecto al derecho notarial democrático.

\section{Palabras clave:}

Derecho penal, invasión notarial, bien jurídico, principio personalístico.

\section{NOTARIAL INVASION AND ITS PENAL JUSTIFICATION AS A MECHANISM OF NOTARIAL PROTECTION: STUDY OF LOCAL LEGISLATION IN JALISCO, MEXICO}

\begin{abstract}
Public trust in Mexico is put in the notary's function; Jalisco, like the other states in the country, has a local legislation to regulate notarial activity, it means, there exist 32 laws. The point is that, as a special regulation, none of them considers a solution to the notarial invasion from one state to another one. Solving the problem with the penal threat might be excessive; however, the objective of this study is to demonstrate its viability. It is proposed to design an autonomous penal type which can stop notarial invasion because this causes, as a multi offensive crime,
\end{abstract}

\footnotetext{
Artículo estudio de la Ley del Notariado de Jalisco, resultado de investigación como miembro del Cuerpo Académico Especialidades Jurídicas en Derecho Público, de la Universidad de Guadalajara.

** Doctor en Derecho Penal y Criminología de la Universidad Complutense de Madrid, profesor investigador titular de la Universidad de Guadalajara, Centro Universitario de la Ciénega, México. El autor agradece la colaboración de Abigaíl Muñoz Lozano y Camerina Orozco Sosa. Correo electrónico: rokame00@hotmail.com.
} 
different damages to legal assets, the first of which is the credibility of public trust. The creation of the penal type called notarial invasion is supported by the theory of the personalistic principle, to set up an offense that is necessary in a society that evolves with respect to the democratic notarial law.

\section{Key words:}

Penal law, notarial invasion, legal assets, personalistic principle.

\section{A INVASÃo NOTARIAL E A SUA JUSTIFICAÇÃo PENAL COMO MECANISMO DE PROTEÇÃO NOTARIAL: ESTUDO DA LEGISLAÇÃO LOCAL DE JALISCO, MÉXICO}

\section{Resumo}

A fé pública no México está depositada na função do notário, Jalisco como os demais estados do país, conta com uma legislação local para regular a atividade do notariado, é dizer, existem 32 leis. A questão é que como regulamentação especial, nenhuma contempla uma solução à invasão notarial de um estado a outro. Possivelmente resolver o problema com a ameaça penal seja um excesso, contudo, neste estudo o objetivo é demonstrar a sua viabilidade. Propõe-se desenhar um tipo penal autónomo, que detenha a invasão notaria, toda vez que ocasiona, como delito pluri-ofensivo, diferentes afetações a bens jurídicos, o primeiro deles a credibilidade da fé pública. A criação do tipo penal invasão notarial é sustentado na teoria do princípio personalístico, para fundar um delito que é necessário numa sociedade em evolução respeito ao direito notarial democrático.

\section{Palavras chave:}

Direito penal, invasão notarial, bem jurídico, princípio personalístico.

\section{INTRODUCCIÓN}

Desde sus primitivas formas de aparición hasta su actual tipificación, es un verdadero problema y objeto de desprotección penal, aquel tipo mal estructurado y mal llamado delito equiparado de usurpación de funciones. Se debe reconocer la naturaleza delictiva que, a la vez, implique delimitar el interés jurídico afectado y que prevalece sobre otros, demarcando y concentrando una nueva figura, misma que puede contemplarse en el Código Penal como invasión notarial. Su desarrollo jurídico penal se resume de manera bifronte: como delito de falsedad o como delito de función, que perjudican al notario.

Ciertamente ha sido un tema resbaladizo con el que el propio Código Penal de nuestra entidad ha tratado de subsanar las debilidades que enfrenta la Ley del Notariado del Estado de Jalisco (México), al equiparar el delito de usurpación de funciones en el artículo 44 de dicha ley, de la siguiente manera:

Se equipara al delito de usurpación de funciones públicas y se sancionará con pena de dos a seis años de prisión y multa de quinientos a mil salarios mínimos vigentes, a quien sin ser notario o siéndolo se encuentre con suspensión o licencia concedida por el titular del Poder Ejecutivo del Estado o sin tener fíat expedido por el Ejecutivo del Estado, ofrezca por cualquier medio de comunicación, prestar servicios notariales dentro del estado de Jalisco o mantenga protocolos, libros, folios, sellos, hologramas, 
hojas membreteadas para la utilización en testimonios, relacionadas con la actividad notarial (Código Penal para el Estado Libre y Soberano de Jalisco aprobado en agosto de 1982).

En todo caso, es una norma importante que viene a introducir en nuestro ordenamiento jurídico un sistema avanzado, moderno y humano de protección notarial, pero que a la vez podría fortalecer esta protección si se retoma la teoría del bien jurídico (Bricola, 1997), los principios generales del derecho penal (Mantovani, 2007 y las nuevas ideas de protección penal, y así lograr verdaderamente sus fines, adoptando estas propuestas, basadas con precisión y acierto, objetivos de tutela con las oportunas precauciones de defensa de la sociedad afectada, pues no solo es la actividad notarial la única lesionada, sino en la cadena de perjudicados involucra a toda la sociedad que requiera servicios notariales, ¿y quién no ha recurrido a un notario en el transcurso de su vida?

El trabajo se sustenta en una clara vocación garantista sobre el notario y el más débil afectado por estas conductas ilícitas (Ferrajoli, 2006). Los criterios orientadores de la Ley del Notariado del Estado de Jalisco, no son claros en este sentido, el bien jurídico no es el señalado, la usurpación de funciones, presenta, frente a la invasión notarial, un carácter esencialmente dirigido a la intervención penal de la impunidad que conduce a una naturaleza formalmente penal pero materialmente inaplicable.

En cuanto a estas y otras deficiencias, la ley ha sido fuertemente criticada por su falta de precisión, y por la timidez con la que trata la protección jurídica del notario. Con semejante sentido y continuidad con el máximo de los rigores científicos, se acerca a la situación del notario ante el derecho penal planteando, como parámetro previo, la importancia de la aplicación de la racionalidad dogmática en el derecho notarial sobre construcciones dogmático-jurídicas que alumbren una estructura sistemática congruente.
Demostrativa la ausencia de protección de la fe pública en el delito en estudio, esta función de control atribuida por el Estado y tutelada por la Ley del Notariado del Estado de Jalisco y del Código Penal, se conduce teleológicamente a evitar la puesta en peligro concreto o la lesión de los bienes jurídicos individuales que pueden verse afectados por el contacto social, por la relación del prestador del servicio-usuario. Expondremos entonces que la protección penal directa de los bienes jurídicos individuales más importantes podría dotar de contenido constitucional la punición de la invasión notarial en algunos supuestos.

\section{LA FUNCIÓN DEL NOTARIO}

El notario realiza una función pública y su actuación la regula la legislación correspondiente a cada estado, de forma tal, que la actividad primordial del notario consiste en dar seguridad y certeza jurídica al estado y a los particulares sobre los hechos o actos que realicen y quieran o deban dar formalidad ante la institución del notariado.

Bernardo Pérez Fernández del Castillo (2009) sostiene que la actividad del notario es amplia; ya que debe escuchar, interpretar, aconsejar a los usuarios del servicio notarial; preparar, redactar, certificar, autorizar, conservar y reproducir los actos y negocios jurídicos. Ejerce una función de orden e interés público, es prestador de un servicio público ya que satisface las necesidades de interés social al autentificar, certificar y dar seguridad jurídica a los hechos, actos y negocios jurídicos de los que da fe. En materia política colabora con las organizaciones políticas y es un respaldo en los procesos electorales.

La actividad del notario es de importancia social y jurídica, pues mediante ésta se "tutela la aplicación de la ley y con ella la del ordenamiento jurídico" (Villalobos, 2005) para así asegurarle a la sociedad "la paz pública y el orden social que salvaguarden la suprema misión del derecho: regular imparcialmente la vida social, facilitando el desenvolvimiento de la comunidad y su progreso por medio de la justicia" (Villalobos, p. 33). 
La principal función del notario consiste en redactar los instrumentos, nos dice Gattari:

Porque de la propiedad, precisión y claridad de los términos usados, como de la disposición de las partes de la escritura, surgirá la mayor o menor pureza en la constitución o expresión de los hechos que se intenta manifestar como exteriorización formal de la voluntad (2008, p.314).

De lo anterior se desprenden dos de los principios que rigen la actividad notarial: la autoría y la legalidad; que resultan ser los principios elementales de la función misma.

Sin embargo, la autoría no solo es la redacción de instrumentos, sino también aconsejar cuál medio jurídico es el que se adecúa a las necesidades de los usuarios del servicio notarial y corroborar si se ajustan o no a las opciones que marca la ley; por lo que en las relaciones contractuales que se llevan en el diario acontecer y en el actual tráfico jurídico, el notario no es un simple asesor $y$ redactor de escrituras, sino que estas se han convertido en una verdadera obra de "ingeniería jurídica en las que no se trata solo de conocer la ley, sino de interpretarla, integrarla y compatibilizarla con otras explorando las opciones que se dejan a la autonomía de la voluntad de las partes" (Ciarreta, Espinosa, Martín \&Zurimendi, 2010, p. 97).

El notario también ejecuta una actividad económica, para ello interviene en el mercado al prestar sus servicios a las personas que lo demanden; esta, deberá cubrirle al notario las obligaciones que correspondan, es decir, le retribuirá por sus servicios y de conformidad con el sistema que fija los precios por los servicios o productos que ofrecen los notarios, conocido como arancel notarial.

El notario tiene el deber de cobrar justamente y según el arancel notarial. Algunos notarios, al favorecer ciertos clientes reduciendo los honorarios establecidos en el mismo, crean competencia desleal en el gremio, pues le quitan el cliente a notarios que aplican el arancel notarial de forma justa y adecuada.

La labor notarial y el notario tienen una función social, en la cual, el notario por el contacto directo que mantiene con la realidad social, despliega su actividad apoyando a las personas y actuando en defensa de los más desprotegidos o de aquellos que desconocen la complejidad de la ley y los alcances de esta; para que así se puedan encontrar en igualdad de condiciones ante los individuos o instituciones con los que podrían contratar; convirtiéndose de esta manera en su natural consejero y defensor, sin dejar de lado la imparcialidad con la que debe dirigir su actuación; deber, que le permite al usuario débil, a diferencia de otros, hallarse debidamente asistido.

El notario en el desarrollo de su función social, tiene la responsabilidad de colaborar con el avance y progreso de la comunidad, por lo que busca una sociedad más justa; y en consecuencia, solo deberá reducir los honorarios en el caso de personas de escasos recursos y en los programas de Gobierno, por ejemplo de escritura de la vivienda popular, de regularización de tenencia de tierra, urbana y suburbana o el llamado, "septiembre mes del testamento" 1 ". Allí no solo el notario se compromete a recortar sus honorarios, sino también las autoridades administrativas simplifican los trámites y disminuyen los impuestos y derechos.

\section{CONCEPTUALIZACIÓN DE LA INVASIÓN NOTARIAL}

Para el diccionario de la Real Academia de la Lengua Española DRAE (1992) la palabra invasión significa acción y efecto de invadir, el misto texto señala que invadior es: "ocupar anormal o irregularmente un lugar". En derecho es el "acto de penetrar sin derecho en un sitio careciendo del consentimiento de su dueño y aun contra su voluntad, o de abrogarse atribuciones o

1 El mes del testamento se lleva a cabo por acuerdo de la Secretaría de Gobernación y la Asociación Nacional del Notariado Mexicano. 
facultades propias de otra persona"(Enciclopedia Universal Ilustrada Europeo Americana Espasa, 2001, p. 1877).

La invasión constituye siempre un atentado contra el derecho constituido, ya se dirija contra la propiedad ajena, para apoderarse de ella, o contra una jurisdicción para usurparla.

Por tanto, es requisito indispensable, para que exista, que se carezca en absoluto de derecho para invadir lo ajeno, y que sin violencia o con ella se realice sin el consentimiento del legítimo poseedor de la cosa o de la función invadida. La entrada de ejércitos o huestes armadas en país extranjero, en clave de guerra, constituye el caso más característico de invasión (Enciclopedia Universal Ilustrada Europeo Americana Espasa, 2001). Así, esta voz la adoptaremos para formular el tipo penal que dará protección a la función notarial.

\section{BASES PARA LA CONSTRUCCIÓN DEL BIEN JURÍDICO PROTEGIDO TUTELADO EN EL DELITO DE INVASIÓN NOTARIAL}

El eje sobre el cual gira un derecho penal garantista es el objeto jurídico penal, esto es, el bien o interés individual o supraindividual (colectivo, público, institucional) que es tutelado por la norma incriminadora (Mantovani, 2007).

Cabe señalar que bien e interés, son conceptos distintos, puesto que el primero indica todo acto que intenta satisfacer una exigencia humana, mientras que el segundo, establece la relación entre bien y sujeto titular del interés y viene señalado como interés de su tutela. No obstante, estos términos se utilizan hoy indistintamente expresando igual realidad desde dos diferentes ángulos y no siendo posible tutelar el uno sin el otro.

Así pues, no es ocioso hablar de la teoría del bien jurídico cuando por medio de su estructura se moldea un código penal, el problema se centra en la discusión que existe respecto de qué bienes jurídicos pueden o deben ser los penalmente protegidos. Precisamente, el tema de nuestra investigación retoma el bien jurídico como condición necesaria de justificación penal y punto de partida, para elaborar una propuesta de reforma a la Ley del Notariado del Estado de Jalisco y de su sistema penal, procurando la inclusión del tipo penal que afecta a la función notarial.

Las tesis innovadoras que de la civilización tienden cada vez a incorporarse en el sistema penal -por los acelerados procesos en el ámbito de las comunicaciones, de las nuevas tecnologías y el imparable desarrollo en materia informática-, buscan recovecos para criminalizar conductas que afecten intereses derivados de estos procesos, lo cual produce a ciencia cierta, el abuso de su protección hipertrofiando el Código Penal y agravando las penas que se vinculan con estos fenómenos.

Estos procesos ulteriormente generan un abuso de poder y se orientan al desprecio por los derechos fundamentales, -al que se le debe ganar terreno-, a través de las ideas liberales que han fortalecido al derecho penal de corte garantista, para la reconstrucción de la herramienta jurídica que descansa en el código penal. Es necesario entonces limitar la discrecionalidad legislativa, sobre la fundamentación de los principios generales de derecho penal, para la creación del delito de invasión notarial como ofensa concreta a un bien jurídico (principio de ofensividad) de las funciones del notario de Jalisco, que se han visto vulneradas por las prácticas nocivas de esta nueva figura que se pretende reconocer.

\section{Límites de selección de bienes jurídicos}

Ahora bien, la existencia material individual y supraindividual de bienes no exige que automáticamente se transformen en bienes jurídico-penales, pues estos no deben recibir una protección formal dentro del derecho penal, dada la selectividad del principio fragmentario, pues para que merezca la tutela penal debe atender su triple dimensión en 
el principio de proporcionalidad (Zamora\&Barba, 2011), dignidad (Zamora, 2004), subsidiariedad (Mantovani, 2007) y fragmentariedad (Palazzo, 1992). Así pues, el uso de una sanción tan grave como la pena requiere del presupuesto de una infracción igualmente grave (Mir, 1997).

A este respecto la doctrina estima que el derecho penal solo protege los bienes jurídicos más valiosos para la convivencia; lo hace además, exclusivamente frente a los ataques más intolerables que puedan ser objetos -naturaleza fragmentaria de intervención penal-, así cuando no existen otros medios eficaces de naturaleza no penal para salvaguardar aquellos -naturaleza subsidiaria de derecho penal-, de esta forma, justificamos la inclusión del delito de invasión notarial, pues el derecho penal presenta necesariamente su carácter fragmentario, pues solo protege los bienes jurídicos más fundamentales, y sobre todo, protege a estos frente a cualquier clase de atentados, en particular, los ataques más intolerables(García, 2003).

En este sentido, podemos justificar la intervención del sistema penal dados los resultados que arroja la impunidad de los actos ilícitos de la invasión, la reiteración de las conductas y la preocupación de los notarios que se ven desprotegidos por el sistema penal actual en Jalisco.

\section{El bien jurídico en el delito de invasión notarial}

La tutela genérica la constituye el normal funcionamiento de la labor notarial, siendo la protección específica la exclusiva legitimidad de esta. De dicho análisis se pueden extraer dos posibles objetos de salvaguarda:

a) La potestad estatal de expedir títulos (fíat).

b) El interés general en una garantía formal de que, los profesionales ejerzan su carrera adecuadamente.

Es decir, el anverso y reverso de un mismo objeto formal de protección, se trata por lo tanto de la exclusiva potestad estatal de expedir títulos (fíat), pues el delito se cometería incluso cuando el mencionado interés general de idóneo ejercicio de notario, mediante garantía formal, no sufriese en modo alguno menoscabo o lesión de ningún género en todos aquellos supuestos en los que el agente efectuase actos propios de una profesión para la que se exige título oficial (fíat), estando en posesión de un título concedido en otro estado.

Ahora bien, la exclusividad se explica en el sentido de la titularidad, competencia e idoneidad para el ejercicio de la función pública de sujetos calificados por el titular del Poder Ejecutivo del estado de Jalisco, siendo este el único que puede otorgarla.

De esta manera, el perjuicio al bien jurídico se podría configurar con la invasión de sujetos a competencias ajenas a la función pública, en nuestro Estado, o estando en posesión de título oficial expedido en otro Estado de la República mexicana, desempeñen su función en algunas de las zonas distribuidas en el Estado de Jalisco.

De esta relación acto-función, se puede señalar que se tutela la función notarial, pretendiendo asegurar que los actos propios de las autoridades o de funcionarios públicos solo se ejecuten por quienes tienen poder $y$ facultades para hacerlo legítimamente. Frente al Estado, esa exclusividad se traduce como fuente productora y que delega autoridad y función pública del principio de autoridad.

A esta exclusividad -como titularidad y competencia en la práctica de la función pública- hay que ajustar la legitimidad requerida por vía de la Ley del Notariado del Estado de Jalisco. La legalidad de las funciones públicas subsiste tanto para su acceso como para su ejercicio, en donde la potestad de otorgar autoridad y la competencia de la función pública se desarrolla desde los parámetros lícitos sin llegar a actuaciones abusivas e impropias.

Entendemos que se requiere la legalidad de la función, una de cuyas bases es la autoridad estatal 
para conferir facultades de decisión o ejecución a determinadas personas y distinguir entre esferas de competencia y los funcionarios. Quien accede o ejerza la función pública fuera de los límites lícitos lesionaría el poder monopólico del Estado que sobresale de las funciones públicas y la competencia e idoneidad de estas.

Por todo lo expuesto, podemos fundamentar la punición de la invasión notarial, en el interés de evitar la intromisión de sujetos ajenos a las funciones notariales en Jalisco, reservando solo para los profesionales calificados y competentes, poseedores del fíat legalmente expedido por el titular del Poder Ejecutivo del estado de Jalisco, toda intromisión al ejercicio de las funciones del notario.

Ante esta situación poco alentadora del sistema de procuración e impartición de justicia por medio del instrumento sancionatorio, el Poder Legislativo y los responsables de la administración de justicia en México, deben reflexionar sobre la urgente necesidad de una profunda y real transformación al derecho notarial. De forma contraria los delitos de invasión notarial aumentarán y afectarán nuestra forma de hacer justicia por cuenta propia, debido a la ineficacia del Estado para dotar de certeza y seguridad jurídica. Por ende, una sociedad que no garantiza a la persona humillada alguna defensa contra los prevaricadores intocables, impunes, genera fatalmente delincuencia de reacción (Mantovani, 1986).

\section{Bases para su destipificación}

Para comprender la practicidad de la creación del tipo penal autónomo de invasión notarial, será imprescindible situarnos en la vulneración del bien jurídico afectado(Barba, 2010), para observar con detenimiento, el significado de una verdadera y extensa tentativa para refundir la parte especial de la Ley del Notariado del Estado de Jalisco sobre el cimiento de una nueva tipología de bienes. De hecho, el bien jurídico se encuentra definido como aquella entidad susceptible de violación, a efectos prácticos; como lesión o puesta en peligro, en esta tesitura, el derecho penal no puede reprimir bienes de escaso valor, por cuanto resguarda la negativa configuración ofensiva de un bien jurídico digno de reconocerse, de no ser así, este último apunte nos trasladaría a sistemas represivos o a Estados totalitarios.

El profesor Ferrando Mantovani (1997) pondera la protección de bienes jurídicos de corte personalístico, esto es, de un modelo de código penal con una función primaria de instrumento de libertad, jerarquizando el sistema de bienes jurídicos según la triple directriz: (i) de la centralidad de la persona humana, fin primero y fin último, alfa y omega del sistema penal; (ii) de la consiguiente suma de distinción entre: bien-fin, constituido de los derechos fundamentales de la persona humana y tutelados como tales; $y$ bienes-medio, constituidos de los bienes individuales patrimoniales y de los bienes ultra individuales (familia, comunidad, del Estado-administración, del Estado unidad y de las instituciones democráticas) a la conservación, dignidad y desarrollo de la persona humana, en su doble dimensión individual y social, y (iii) de la consecuente centralidad de los delitos contra la persona, que propiamente por su prioridad deben, también topográficamente, abrir la parte especial del código personalístico, seguidos de los delitos contra bienes-medio(Mantovani, 1997).

Con respecto al contenido personalístico-solidarístico, que con reiteración expusiera amplia y extensamente y con verdadera finura Mantovani (1997)-el cual estudia al hombre en una triple dimensión especialmente reconocida (hombrevalor, hombre-persona y hombre-fin), y a la vez le otorga la máxima categoría como bien a tutelar, colocándole el cetro y la corona, para construir la expresión penal del moderno Estado social de derecho-, para el autor en mención, es en el hombre donde se depositan todos los demás derechos y libertades que conceden las constituciones y leyes secundarias, y así cumplir con la conservación de la dignidad y desenvolvimiento de la persona humana, porque solo a través de esta formulación se podrá mantener el equilibrio de la justicia. Sin el reconocimiento de este con- 
tenido, nos trasladaríamos a los planteamientos utilitarios del Estado que recurre a la pena, para adoptar bienes jurídicos que afectan a intereses políticos como la seguridad de la nación; es decir, a criminalizar atentados contra bienes de intereses secundarios para la conservación del poder estatal, tal y como lo establecen algunos de los códigos penales de México.

La conducta de invasión recae sobre funciones del notario, constituyéndose en su objeto material. Así, las funciones del notario o actos propios del notario se determinan como un marco que delimita actividades y atribuciones de la administración pública; sin embargo, esto no implica necesariamente que se comprenda la totalidad de las actividades públicas. La expresión "función notarial" como elemento normativo indica el contenido de lo que se va a invadir. Estas son actividades reservadas para sujetos, a los cuales el Estado los considera competentes conforme a la normatividad vigente.

Para la interpretación del tipo penal, debemos definir algunas características de las funciones notariales para entender qué es lo que se va a invadir. Como ya adelantamos, las funciones notariales son exclusivas ("actos propios"), es decir, se ubican dentro de la idoneidad y atribuciones designadas normativamente a aquellos aptos para ser notarios. Una cuestión a resolver son los casos de funciones compartidas o desarrolladas sucesivamente sea con otros funcionarios o servidores, o inclusive por particulares.

De confirmarse, cualquier intento de imputar invasión a estos devendría en ineficaz por no guardar la función pública exclusividad alguna. Empero, en el supuesto de la acción que sea compartida por otros funcionarios, la exclusividad se reservapara estos y se opone para terceros, quienes se constituirán en posibles sujetos activos. Por todo esto, podemos afirmar que habría de tratarse de un acto que no corresponde en medida alguna a la competencia de esa persona, ni siquiera a la que pudiera tener en concurso con otros, pero es razonable que el autor del delito no sepa cuáles son las competencias concretas que tiene el notario por quien se hace pasar, pues lo importante realmente es que él carece de esa condición.

\section{ANEXOS}

Gráfica1. Número de denuncias presentadas ante la Procuraduría General de Justicia del Estado de Jalisco por el delito de usurpación de funciones públicas o de profesión en los años 2008 , 2009 y 2010

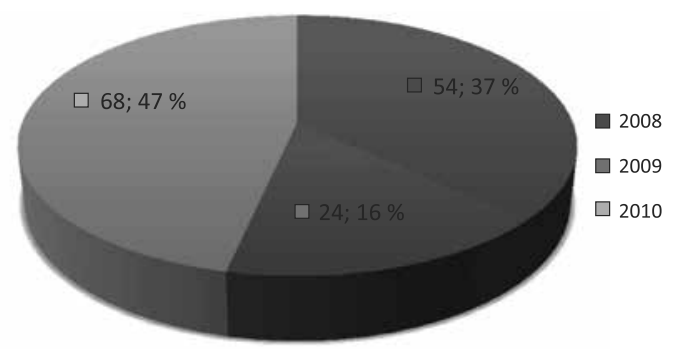

Fuente:Coordinación General Jurídica y de la Unidad de Transparencia e Información de la Procuraduría General de Justicia del Estado de Jalisco; a través de la solicitud de información pública que se presentó por escrito, a la que se le da folio electrónico número 00772211 y se relaciona con la gráfica 1 del presente trabajo de investigación.

Gráfica 2. Estadísticas que establecen el porcentaje en aumento de los actos inscritos desde el año 2008 al 2010 en el Registro Público de la Propiedad y el Comercio en el Estado de Jalisco

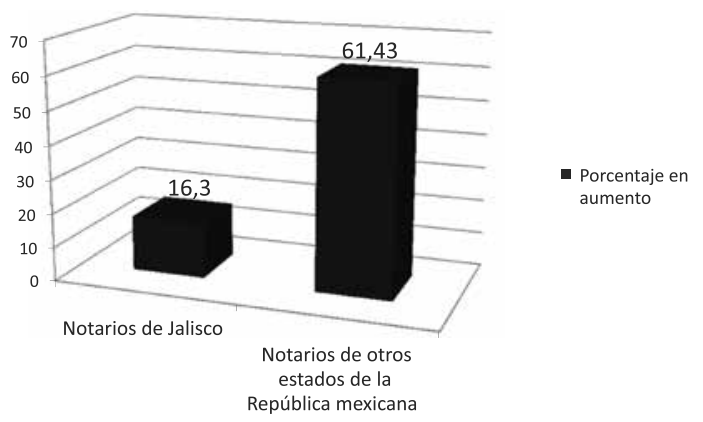

Fuente: Unidad de Transparencia e Información de la Secretaría General de Gobierno del Estado de Jalisco; información proporcionada a través de solicitud por escrito, misma que fue respondida en versión digital. 
Tabla 1. Resultados de cuestionario realizado a la muestra de notarios del estado de Jalisco

\begin{tabular}{|c|c|c|c|c|c|}
\hline \multirow[t]{2}{*}{ Pregunta } & \multicolumn{5}{|c|}{ Respuesta } \\
\hline & Sí & No & Total & & \\
\hline & $\begin{array}{l}\text { Número } \\
\text { notarios }\end{array}$ & $\begin{array}{c}\text { Propor- } \\
\text { ción }\end{array}$ & $\begin{array}{l}\text { Número } \\
\text { notarios }\end{array}$ & Proporción & $\begin{array}{l}\text { Número } \\
\text { notarios }\end{array}$ \\
\hline $\begin{array}{l}\text { ¿Cree usted que la invasión notarial es un } \\
\text { problema relevante para los notarios del } \\
\text { estado de Jalisco? }\end{array}$ & 30 & 100:100 & 0 & $0: 100$ & 30 \\
\hline $\begin{array}{l}\text { ¿Considera usted que la solución legislati- } \\
\text { va (artículo } 44 \text { de la Ley del Notariadodel } \\
\text { Estado de Jalisco) a esta problemática es } \\
\text { la idónea? }\end{array}$ & 8 & $27: 100$ & 22 & 73:100 & 30 \\
\hline ¿Ha sido víctima de esta conducta? & 20 & $67: 100$ & 10 & $33: 100$ & 30 \\
\hline ¿Ha incurrido usted en invasión notarial? & 1 & $3: 100$ & 29 & $97: 100$ & 30 \\
\hline $\begin{array}{l}\text { ¿Considera usted que se debería crear un } \\
\text { nuevo tipo penal específico para proteger } \\
\text { esta problemática? }\end{array}$ & 23 & $77: 100$ & 7 & 23:100 & 30 \\
\hline
\end{tabular}

Fuente:Cuestionario realizado por Abigaíl Muñoz Lozano, en el cual la muestra se toma de conformidad con el sistema del cálculo del tamaño de la muestra que ofrece Consulta Mitofsky en su página de Internet y que tiene las siguientes características:

Error máximo aceptable para el estimador: $10 \%$.

Nivel de confianza: $75 \%$.

Efecto de diseño: $1 \%$.

Tasa de respuesta: $100 \%$

Tamaño aproximado de la proporción a estimar: $50 \%$.

Tamaño de la población de notarios en el estado de Jalisco: 314 .

A través del sistema de proporciones, se determinó el vínculo existente entre la muestra de notarios a los que se les aplicó el cuestionario y el universo de los mismos.

Tabla 2. Actos inscritos en el Registro Público de la Propiedad y el Comercio por Notarios del estado de Jalisco y otros estados de la República mexicana en los años 2008, 2009 y 2010

\begin{tabular}{|c|c|c|c|}
\hline \multicolumn{4}{|c|}{ Actos inscritos } \\
\hline \multirow{2}{*}{ Por notarios de: } & \multicolumn{3}{|c|}{ En los años } \\
\cline { 2 - 4 } & $\mathbf{2 0 0 8}$ & $\mathbf{2 0 0 9}$ & $\mathbf{2 0 1 0}$ \\
\hline Jalisco & 326.145 & 339.863 & 379.311 \\
\hline Otros estados de la República Mexicana & & & \\
& 13.041 & 16.258 & 26.246 \\
\hline
\end{tabular}

Fuente: Unidad de Transparencia e Información de la Secretaría General de Gobierno del Estado de Jalisco; información proporcionada a través de solicitud por escrito, misma que fue respondida en versión digital.

2 "Confianza indica la probabilidad de que nuestro estimador se acerque al verdadero valor a una distancia menor al error fijado. Error máximo admisible, representa el valor máximo del error que estamos dispuestos a aceptar con la confianza también fija.

Proporción a estimar, significa la proporción de elementos de la población que poseen una característica. Tasa de respuesta, es el porcentaje de respuestas completas que esperamos obtener para nuestra variable. Tamaño de la población, es el número de elementos en la población que se mide" (Consulta Mitofskyhttp://consulta.mx/web/index.php/estudios-e-investigaciones/ tamano-de-muestra). 


\section{CONCLUSIONES}

1. Del desarrollo de la presente investigación se desprende la importancia de la función notarial; al estar reconocida, regulada y supervisada por el Estado y ser de orden público; ya que otorga seguridad jurídica en los hechos, actos y negocios jurídicos que llevan a cabo los seres humanos y que tienen que ver con ellos desde su gestación $e$ incluso después de su muerte.

2. La actividad del notario es de gran importancia para alcanzar el sano desarrollo social y económico de una sociedad, razón por la cual la función notarial debe protegerse de forma eficaz y no tímida como se encuentra en la actualidad, tal y como se demostró a lo largo de este artículo. Una proporción de 67 de 100 notarios del estado de Jalisco manifestó al responder al cuestionario que se aplicó aquí, que ha sido víctima de la conducta conocida como invasión notarial, al mismo tiempo que 100 de 100 notarios consideran dicha conducta como un problema significativo y que afecta al gremio notarial. Del año 2008 al año 2010 aumentó en un $61,43 \%$ la actividad que llevan a cabo los notarios de otros estados de la República en el Registro Público de la Propiedad y del Comercio en el Estado de Jalisco; mientras que la actividad de los notarios del estado de Jalisco solo se incrementó en un 16,30\%.

3. El delito equiparado de usurpación de funciones, ha sido interpretado, legítimamente, con arreglo a dos sistemas político-criminales muy distintos: por un lado el legado jurídico penal español, en relación con los fines y objetivos que persigue este delito, alejado del verdadero interés que debe proteger la norma respecto a la función notarial; por otro, la construcción de un tipo penal fundamentado en el principio personalístico, es decir, en la base de un derecho penal garantista, de mínima intervención, de ultima ratio y de ofensividad y ello ha tenido su reflejo en la concreción del bien jurídico protegido y en la configuración del tipo penal que garantice la función notarial.

4. Estrechamente relacionada al tema del bien jurídico se encuentra la naturaleza jurídica del delito. Cabe plantearse la índole jurídica del tipo como irrelevante, en la medida en que no fuese la sociedad o colectividad el bien jurídico protegido, frente a la falta de capacitación y peligros que de la conducta invasora se podría derivar. Por lo tanto, la ubicación sistemática es y deberá ser, delitos contra las actividades del notario, en un título especial autónomo.

\section{REFERENCIAS}

Barba, R. (2010).Derecho penal de la ofensa como principio recodificador. México D. F. Angel editor.

Bricola, F. (1997).Política criminale e scienza del dirittopenale. Milano, Il Mulino.

Ciarreta, A., Espinosa, A., Martín, J. M. \&Zurimendi, I. A. (2010). El estado de la competencia en la profesión de notario. Madrid: Marcial Pons.

Diccionario de la real académia de la lengua española, (1992) Madrid, Espasa.

Enciclopedia Universal Ilustrada Europeo Americana, (2001), Madrid, Espasa.

Ferrajoli, L. (2006).Direito e razão teoria do garantismo penal, 2DA. edição, Sao Paulo: editora revista dos tribunais.

García, P. A. (2003).Introducción al derecho penal, parte general. Madrid, editorial de la Universidad Complutense de Madrid.

Gattari, C. N. (2008). Manual de derecho notarial ( $2^{\mathrm{a}}$ ed.). Buenos Aires: Abeledo-Perrot.

Mantovani, F. (1986). Le modifiche al sistema penale del 1981: Risultati ed indicazioni di una ricerca empirica. Rivista Italiana di Diritto e procedura penale (RIDDPP)DPP.Milano,Giuffre. 
Mantovani, F. (1997a). Il principio di offensività nello schema di delega legislativa per un nuovo códice penale. Rivista italiana di diritto e procedura penale (RIDDPP)RIDDP.Milano, Giuffre.

Mantovani, F. (1997b). Principi di diritto penale(2a . ed.). Milano,CEDAM.

Mantovani, F. (2007). Dirittopenale parte generale (3 ${ }^{\text {a }}$ ed.). Minalo, CEDAM.

Mir, S. (1997).Derecho penal parte general. Barcelona Promociones y Publicaciones Universitarias PPU.

Palazzo, F. (1992). Tecnica legislativa e formulazione della fattispecie penale in una recente circolare, ecc.Cassazione Penalevolumen 42, Milano, Giuffre.

Pérez, B. (2009). Derecho notarial (16 ${ }^{\mathrm{a}}$ ed.). México D. F.: Porrúa.

Villalobos, J. (2005.). El notariado como institución jurídica. Recuperado dehttp://www. revistanotarios.com/?q=node/414 http://www. juridicas.unam.mx/publica/librev/rev/podium/ cont/32/pr/pr11.pdf

Zamora, A. (2004).Cuerpo del delito y tipo penal. México D. F. Ángel Editor.

Zamora,A.\& Barba, R. (2011).Teoría jurídica del delito. México D. F.Ángel Editor. 